\title{
Acute Lymphoblastic Leukemia with Primary Testicular Involvement in a Pre-pubertal Male: A Case Report
}

\author{
Patrick Olanrewaju Osho ${ }^{1, *}$, Matilda Adesuwa Osagie Ojo ${ }^{1}$, Eevenly Salawa Osho², \\ Olufunke Caroline Odunlade ${ }^{3}$, Oluwatosin Idowu Oni ${ }^{4}$ \\ ${ }^{1}$ Department of Haematology \& Blood Transfusion, Faculty of Basic Clinical Sciences, University of Medical Sciences, Ondo-City, Nigeria \\ ${ }^{2}$ Department of Radiology, Faculty of Basic Clinical Sciences, University of Medical Sciences, Ondo-City, Nigeria \\ ${ }^{3}$ Department of Paediatrics, Faculty of Clinical Sciences, University of Medical Sciences, Ondo-City, Nigeria \\ ${ }^{4}$ Department of Haematology/Virology, University of Medical Sciences Teaching Hospital, Akure, Nigeria
}

Email address:

droshopo@gmail.com (P. O. Osho),matildaojo4@gmail.com(M. A. O. Ojo), salewaosho@gmail.com (E. S. Osho), drolufunky@gmail.com (O. C. Odunlade),godsprince805@gmail.com (O. I. Oni)

${ }^{*}$ Corresponding author

\section{To cite this article:}

Patrick Olanrewaju Osho, Matilda Adesuwa Osagie Ojo, Eevenly Salawa Osho, Olufunke Caroline Odunlade, Oluwatosin Idowu Oni. Acute Lymphoblastic Leukemia with Primary Testicular Involvement in a Pre-pubertal Male: A Case Report. Cancer Research Journal.

Vol. 8, No. 2, 2020, pp. 42-44. doi: 10.11648/j.crj.20200802.14

Received: May 22, 2020; Accepted: June 10, 2020; Published: July 4, 2020

\begin{abstract}
Acute lymphoblastic leukaemia is the most common malignancy in paediatric patients; its diagnosis is usually easy to establish as malignant lymphoblasts invade the bone marrow and peripheral blood. Patients with Acute lymphoblastic leukaemia (ALL) may initially present with pancytopenia and a hypoplastic or hyperplastic bone marrow. Fever is common at presentation, and despite neutropenia, sepsis is rarely seen. Other common clinical manifestations include fatigue, pallor, petechiae, bleeding, lymphadenopathy and hepatosplenomegaly. Presentation with primarily testicular disease is exceedingly rare in acute lymphoblastic leukemia. The unusual presentation of a primary left testicular involvement in ALL is being highlighted in this case report. We present an 11 year old boy who presented with fever, generalized body pain, abdominal discomfort as well as left testicular swelling. Bone marrow studies, Full blood count and peripheral blood film appearance were typical of acute lymphoblastic leukaemia. Ultrasound findings showed left scrotal enlargement with reduced and coarse parenchymal echotexture, while cytogenetic studies revealed positive Philadelphia chromosomes. There was good response to standard ALL therapy. Clinical remission with normal left testicular size was noted at the end of induction phase of therapy.
\end{abstract}

Keywords: Acute Lymphoblastic Leukemia, Positive Philadelphia Chromosomes, Left Testicular Enlargement

\section{Introduction}

Acute lymphoblastic leukemia (ALL) is the most common type of malignancy in pediatric patients. Its diagnosis is usually easy to establish as malignant lymphoblasts invade the bone marrow and peripheral blood. It is estimated that 2500 to 3500 new cases of B-ALL are diagnosed annually with an incidence of 3.8 cases per 100,000 [1]. In the most recent WHO classification of hematological malignancies, precursor lymphoid neoplasms are divided into two broad categories based on cell lineage: B lymphoblastic leukemia/lymphoma (B-ALL/B-LBL) and T lymphoblastic leukemia/lymphoma (T-ALL/T-LBL) [2]. Patients with acute lymphoblastic may initially present with pancytopenia and a hypoplastic or hyperplastic bone marrow. B-ALL is a neoplasm of precursor cells committed to the B-cell lineage, (B-lymphoblasts) involving bone marrow (BM) and peripheral blood (PB), which is the most typical presentation. Clinically, a case is defined as B-ALL if there are $>25 \% \mathrm{BM}$ lymphoblasts with or without involvement of nodal or extranodal sites. In contrast, B-LBL is confined to a mass lesion with no or minimal evidence of peripheral blood and bone marrow involvement. However, extra-medullary involvement is frequent, with particular predilection for central nervous system, lymphnodes, soft tissue, skin, and spleen. Mediastinal masses are found infrequently [3]. 
Diagnosis and classification of leukemias are based on bone marrow examination to determine the immunophenotype (lineage) and cytogenetic/molecular abnormalities [4]. Leukemic cells are able to infiltrate various extramedullary tissues during the disease process [5]. Studies have showed that testis is a sanctuary site $[6,7]$ Testicular infiltration more commonly occurs later during the course of disease and at relapse [7]. Initial presentation with primarily testicular disease is exceedingly rare $[8,9]$. Fever is commonly noted at presentation, with other clinical manifestations which may include fatigue, palor, petechiae, bleeding, lymphadenopathy and hepatosplenomegaly [3].

\section{Case Report}

An 11-year-old male presented with fever, generalized body pain, abdominal discomfort and left testicular swelling. Fever and the associated symptoms have been recurrent over a period of 4 weeks, while the left testicular swelling was noticed a week prior to presentation. The testicular swelling was painless and had increased slowly over the period. On examination, he was mildly pale, febrile $\left(\mathrm{T}-38^{\circ} \mathrm{C}\right)$, but not jaundiced. Abdominal examination revealed moderately enlarged spleen and liver. Both testes were palpable in the scrotum. The right testis was of normal size, while the left testis was enlarged, firm to hard in consistency but did not appear inflamed and it was not tender. An initial assessment of Sepsis was made with a differential of Lymphoproliferative disorder in view. Investigations done include a full blood count which showed a low PCV (29.4\%), Haemoglobin $(9.1 \mathrm{~g} / \mathrm{dL})$, White blood cell $\left(11,500 / \mathrm{cmm}^{3}\right)$, neutrophils $(75.5 \%)$, lymphocyte $(16.6 \%)$, increased platelets $\left(513,000 / \mathrm{cmm}^{3}\right)$, PCT $(0.49 \%)$, Red blood cell $\left(3.39 * 10^{12} / \mathrm{L}\right)$ and $\mathrm{MCHC}(30.9 \mathrm{~g} / \mathrm{L})$. The basophil, eosinophil, monocytes, $\mathrm{MCV}$ and $\mathrm{MCH}$ were in normal reference range. The morphology of the blood revealed anisopiokilocytotic, polychromacial, hypochromatial and microcytic red blood cell with white blood cell showing marked leukocytosis with prominent small matures lymphocytes and large lymphoid cells with loose chromatin pattern and a few thin rim of basophilic cytoplasm with nucleoli (lymphoblast) and platelets with normal morphology. Bone marrow studies showed leukaemic blast cells $>25 \%$. Ultrasound findings in Figure 1 revealed left testicular enlargement with reduced and coarse parenchymal echotexture. Molecular cytogenic analysis showed Philadelphia chromosome variant (e1a2/e19a2) by the BCR-ABL detection manifested by P190 and P230 clinical proteins (Table 1). Biochemical results were within reference range. Our revised diagnosis was Acute Lymphoblastic Leukaemia with primary testicular involvement. There was no change in the size of the left testis despite use of standard antibiotics for one week. After making the diagnosis of ALL, he was commenced on standard ALL therapy (a high dose combined systemic and intra-thecal chemotherapy). All other supportive treatment were included in the treatment. Patient had clinical remission documented at the end of induction and defined by resolution of left testicular swelling, other symptoms and signs of disease and hematological parameters returning to normal evident by normal complete blood count and bone marrow blast less than $5 \%$. We were not able to complete the whole course of therapy for this patient in our center, as he was referred to another treatment facility. This was because of the problems encountered from out of pocket payment for drugs and also because he could access free drugs from the referral center.

\section{Discussion}

The testes have long been considered a sanctuary site for leukemic cells [6]. Testicular relapses in acute lymphoblastic leukaemia, tends to account for a major proportion of the poor outcome of disease in boys compared with girls. Primary involvement of the testes in ALL is rare $[8,9,10]$. The testicular examination in this patient at presentation was not suggestive of an acute inflammatory process despite the presence of fever. The absence of scrotal tenderness and the firm to hard nature of the testes made the suspicion of testicular malignancy likely in this patient. Considering the patients' age and other associated clinical features an acute leukaemia with primary testicular involvement was considered, even though a primary testicular disease is a rare occurrence. Primary testicular lymphoblastic leukemia is a systemic process and treatment should be providd to minimize recurrence. Two other studies have earlier reported testicular involvement in ALL [8, 9]. One is an adolescent with unilateral enlargement of the left testis while the other case occurred in a 77 year old elderly gentleman who presented with right testicular and vertebral involvement. First case was treated with chemotherapy and had orchiectomy done, while the elderly refused surgery however both had good responses to chemotherapy.

Barredo and colleagues [11] in their study have demonstrated the use of intensive systemic chemotherapy for isolated testicular relapse (ITR) in acute lymphoblastic leukemia as some patients obtained complete remission following the use of high dose chemotherapy thus limiting the use of testicular radiation so as to prevent long term sequelae. Talekar et al [12] showed that Anti-CD19 CAR-T cell therapies have shown high efficacy in inducing durable marrow responses in patients with relapsed/refractory CD19+ ALL. This also shows that some patients' does not requires surgery or irradiation in testicular relapse or primary testicular leukemia. In this patient, even though the disease was not isolated to the testes nor a relapse, there appeared to be a good response to cytotxic drugs with resolution of testicular swelling, without recourse to surgery or irradiation.

\section{Conclusion}

We have described a rare occurrence of primary testicular involvement in ALL and the favorable response to cytotoxic drug was also noted in this report. Those with isolated testicular relapse have also shown good response to therapy. Patients with testicular involvement in ALL should be aggressively treated as they stand a good chance of having a 
long term event free survival.

Table 1. Molecular Cytogenetic analysis using PCR BCR-ABL detection. The result showed Philadephia chromosome positive variant ela2/e19a2 (primer extension).

\begin{tabular}{lll}
\hline Variant & Associated Clinical protein & Associated Disease \\
\hline $\mathrm{b} 2 \mathrm{a} 2 \& \mathrm{~b} 3 \mathrm{a} 2$ & $\mathrm{P} 210$ & Classical CML \\
$\mathrm{e} 1 \mathrm{a} 2$ & $\mathrm{P} 190$ & ALL or Classical CML \\
$\mathrm{e} 19 \mathrm{a} 2$ & $\mathrm{P} 230$ & CML Patient with breakpoint in Micro BCR (N-bcr) \\
\hline
\end{tabular}

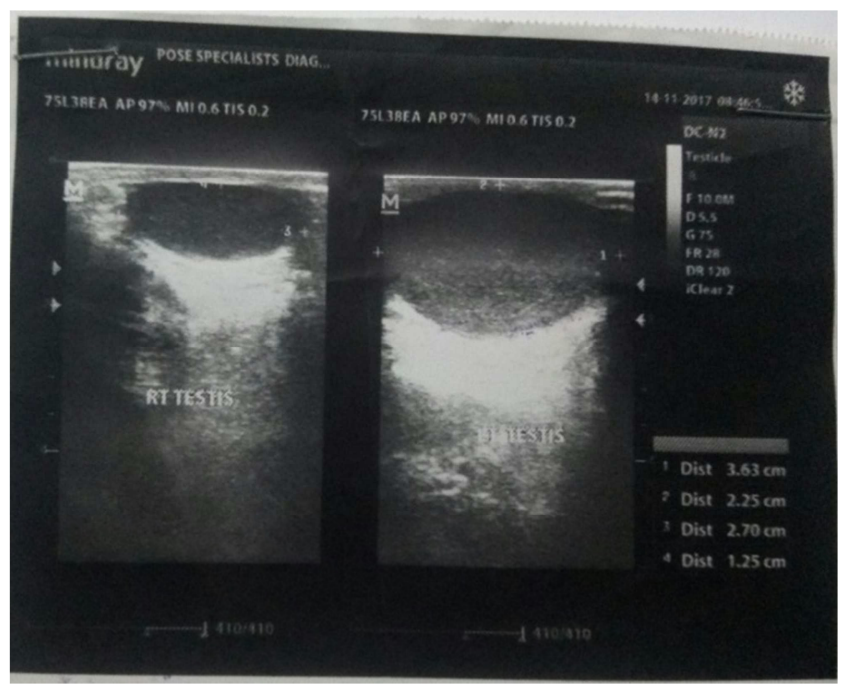

Figure 1. Right and left scrotal scan at presentation.

\section{Declaration}

We hereby state that there is no conflict of interest in this report.

\section{References}

[1] The National Cancer Institute's Physician Data Query $\left(\mathrm{PDQ}^{\circledR}\right)$ Cancer Information Summaries (https://www.cancer.gov/publications/pdq). Last accessed June $5,2020$.

[2] Sherdlow, S. H., Campo, E. Pileri S. A, Harris, N. L. Stein H, et al (2016). World Health Organization classification of tumors of haematopoietic and lymphoid tissues. Blood; 127 (20): 2375-2390.

[3] Kaplan J. A. (2019) Leukemia in Children. Pediatrics in Review. 40 (7): 319-333.
[4] Ashok V, Ranganathan R, Chander S and Sundareshan T. S. (2017). Comparison of Diagnostic Yield of a FISH Panel Against Conventional Cytogenetic Studies for Hematological Malignancies: A South Indian Referral Laboratory Analysis Of 201 Cases. Asian Pac J Cancer Prev. 29; 18 (12): 3457-3464.

[5] Abdolkarimi Babak, Shahriari Mahdi, Zareifar Soheila and Zia Obeydavi (2019) How I Treat Isolated Extra Medullary Acute Lymphoblastic Leukemia? Int J Cancer Res and therapy. $4 ; 2: 1-2$.

[6] Martins A. G, (2018). Testicular Relapse in Acute Lymphoblastic Leukemia (ALL): Guidelines Martins, Journal of Leukemia. 6: 2.

[7] Pui C H. (2018) Is testicular irradiation necessary for patients with acute lymphoblastic leukemia and testicular relapse? Pediatr Blood Cancer. 65: e26977-e26978.

[8] Boddu P, Cameron Yin C, Kanagal-Shamanna R, Tang G, Thakral B, et al (2017). An Unsuspected Finding of $t(9 ; 22)$ : A Rare Case of Philadelphia Chromosome-Positive BLymphoblastic Lymphoma Case Reports in Hematology. 2017; 4-9.

[9] Binesh F, Yazdi M F, Jenabzadeh A, Hosseini S, Massum R. (2016) Primary Testicular Pre-B Lymphoblastic Lymphoma. APSP Journal of Case Reports. 24; 7 (2): 15-19.

[10] Togo B, Traore F, Doumbia AK, Togo P, Diall H, et al. (2018) Childhood acute lymphoblastic leukemia in sub Saharan Africa: 4 years' experience at the pediatric oncology unit Bamako, Mali. J Child Adolesc Health. 2 (2): 24-6.

[11] Barredo JC, Hastings C, Lu X, Devidas M, Chen Y, et al. (2018) Isolated late testicular relapse of B-cell acute lymphoblastic leukemia treated with intensive systemic chemotherapy and response-based testicular radiation: A Children's Oncology Group study. Pediatr Blood Cancer. 65: e26928.

[12] Talekar MK, Maude SL, Hucks GE, Hucks GE, Motley LS, et al. (2017). Effect of chimeric antigen receptor-modified T (CAR-T) cells on responses in children with non- CNS extramedullary relapse of $\mathrm{CD} 19+$ acute lymphoblastic leukemia (ALL). J Clin Oncol. 35: 10507. 